\title{
Repeat \\ non-fatal suicidal behaviour at Johannesburg Hospital
}

\author{
M Y H Moosa, MMed (Psych), FC Psych \\ F Y Jeenah, MMed (Psych) \\ M Vorster, PhD (Psych), MMed (Psych) \\ Department of Neurosciences, Division of Psychiatry, \\ University of the Witwatersrand, Johannesburg
}

Objective. To describe the characteristics of non-fatal suicide behaviour (NFSB) in a group of patients and to determine factors, if any, that may be associated with repetition of this behaviour.

Method. The study included all patients treated for NFSB at Johannesburg Hospital during the period August 2002 October 2002. The information was gathered by means of a structured questionnaire designed to evaluate characteristics of the behaviour.

Results. The study sample comprised 43 patients with NFSB (mean age 29.7 years, range of 16 - 75 years), of whom 26 $(60 \%)$ were female. Sixty-three per cent of the patients overdosed with medication and 33\% ingested household poisons. Events that precipitated the event included relationship problems (70\%), illness (12\%), financial difficulties (9\%), and depressed mood (9\%). In $65 \%$ of patients the behaviour was impulsive. Factors associated with non-fatal repetition included being in the 18 - 30-year age group $(76 \%)\left(\chi^{2}=6.74, p<\right.$ 0.05); being female (90\%) $\left(\chi^{2}=4.75, p<0.05\right)$; having children (90\%) $\left(\chi^{2}=4.72, p<0.05\right)$; a past psychiatric history $(50 \%)\left(\chi^{2}=4.08, p<0.05\right)$; and the current attempt deemed medically serious $(50 \%)\left(\chi^{2}=6.67, p<0.05\right)$.

Conclusions. NFSB is a major problem in South Africa and the incidence is still increasing. Hospital-based interventions following admission are recommended to reduce repeat attempts in such patients. Significant factors associated with non-fatal repetition include among others, a history of a previous medically serious attempt and/or a known psychiatric illness.
About one-third of the general population has, at some point, experienced thoughts of self harm. ${ }^{13}$ Deaths resulting from homicide and unintentional injury usually outnumber those resulting from fatal suicidal behaviour (FSB). ${ }^{4}$ Although it is estimated that worldwide about $25 \%$ of FSB is preceded by nonfatal suicidal behaviour (NFSB) in the preceding year, importance of the latter is usually under-estimated.

There is considerable debate about the underlying causes and the manner in which biological and psychological factors interact in NFSB. Reported risk factors for this behaviour include a history of a psychiatric disorder, ${ }^{6.9}$ advancing age, ${ }^{10-14}$ living alone $^{15}$ or in a low-income area, ${ }^{10}$ current mental illness, somatic illness ${ }^{16-19}$ and the abuse of alcohol and drugs. ${ }^{15}$ Other factors are exposure to various forms of stress ${ }^{14,2025}$ (adversity, discrimination, economic hardship, marital problems, and social disputes). There is also a significant association between having a friend or relative who committed FSB and the individual's attitude towards this behaviour. ${ }^{26}$ Young females have much higher rates of $\mathrm{NFSB}^{23}$ but lower rates of FSB than males. ${ }^{10,11,21222728}$

Common methods employed in NFSB include the ingestion of harmful substances (paraffin, pesticides or battery acid ${ }^{2225}$, overdosing with medicines, ${ }^{23} 24$ use of sharp weapons, and attempted hanging. ${ }^{26}$ In many cases the behaviour can be categorised as demonstrative rather than genuine. ${ }^{25}$ The major intentions or reasons given for committing this behaviour are 'failing to solve problems' and 'mental illness'. ${ }^{26}$

A previous episode of NFSB ranks as one of the major risk factors for future FSB, as does recent discharge from inpatient psychiatric care., 9629 About 1 in 6 patients repeat the behaviour over the next year, and 1 in 4 after 4 years. Nonfatal repetition is also associated with unemployment, increasing severity of suicidal ideation, previous psychiatric treatment and some personality disorders. ${ }^{30,31}$

South Africa is a society in a state of transition and its citizens have been and continue to be severely traumatised. ${ }^{32}$ NFSB appears to be on the increase as people struggle to come to 
terms with the effects of former South African racial policies, and related sociocultural, socioeconomic and other pressures. It is necessary to ascertain the characteristics of NFSB across our various sociodemographic groups. In a previous report ${ }^{33}$ a group of patients with NFSB was compared with a control group without this behaviour. The aim of the present study was to describe, in this same group of patients, the characteristics of the NFSB and to determine factors, if any, that may be associated with repetition of this behaviour.

\section{Method}

The study subjects included all patients treated for NFSB at the Johannesburg Hospital adult medical emergencies ward during the period August 2002 - October 2002. They were interviewed approximately 24 hours after admission or when medically stable.

\section{Assessment}

After obtaining informed consent psychiatry registrars interviewed the patients. All the interviewers received training before the study to improve inter-rater validity and reliability. Data were obtained using a structured questionnaire designed to evaluate subject characteristics (marital status, family history, employment status, highest level of education achieved, current accommodation, etc.) and factors associated with the behaviour (method employed, precipitating event, premeditation, leaving a suicide note, feelings about the outcome, etc.) The seriousness of the attempt was determined by the subject's physical status and by means of laboratory investigations.

All subjects gave written informed consent to participate in the study (in the case of subjects under 18 years of age, consent was obtained from the parents, with assent from the patient). The study was approved by the Committee for Research on Human Subjects, University of the Witwatersrand.

\section{Statistical analysis}

Descriptive statistics of variables were computed as mean and frequencies (count and percentages). The two-sample ktest was used to compare the continuous characteristics (age) between the groups. The chi-square test and Fisher's exact test were used to determine the relation between categorical characteristics. Pearson's correlation coefficient $(r)$ was used to describe any correlations between variables. All analyses were done using the Statistical Package for Social Sciences 10.0 for Windows (SPSS Inc., Chicago, III.) A value of $p<0.05$ was considered significant.

\section{Results}

The subjects comprised 43 patients with NFSB (mean age 29.7 years, range 16 - 75 years), of whom $26(60 \%)$ were female.

Sixty-three per cent of the patients overdosed with medication while 33\% ingested household poisons (Table I). The classes of medication used for overdosing were influenza preparations (23\%), benzodiazepines (17\%) and analgesics (23\%). Events that precipitated the behaviour included relationship problems (70\%), financial difficulties (9\%), illness (12\%) and a depressed mood (9\%). The behaviour was often impulsive (65\%), carried out when the patient was alone $(79 \%)$, and occurred most commonly during the daytime (67\%). Only 2 patients left a note of their intention.

Seventy-two per cent of the attempts were deemed not medically serious and the majority of subjects were discharged from hospital for ambulatory care. Sixty-five per cent of the patients indicated that they had a desire to die at the time of attempt while $21 \%$ said they were trying to make a point. At the time of interview, $58 \%$ of the patients were glad that they had survived and the majority (77\%) said they had no intention of repeating the behaviour.

There was a significant association between the seriousness of the behaviour and the behaviour being premeditated $\mid p=$ $0.017)$, a past history of NFSB ( $p=0.005)$, a family history of NFSB ( $p=0.012$ ), a family history of psychiatric illness ( $p=$ $0.032)$, and a history of sexual or physical abuse ( $p=0.001)$.

Patients were significantly more likely to be admitted to hospital if they had a history of a previous NFSB ( $p=0.009)$ or if they had a low level of education ( $p=0.039)$. They were more likely to be treated as outpatients if they had a family history of psychiatric illness ( $p=0.044)$ or if they had children of their own $(p=0.004)$.

Ten patients had a history of a previous episode of NFSB (Table II). Factors associated with non-fatal repetition included being in the 18 - 30-year age group (76\%) $(p<0.05)$, being female (90\%) ( $p<0.05)$, having children (90\%) ( $p<0.05)$, a past psychiatric history (50\%) ( $p<0.05)$, and a current attempt that was deemed medically serious (50\%) $(p<0.05)$. 


\begin{tabular}{|c|c|c|}
\hline Characteristics & $N$ & $\%$ \\
\hline \multicolumn{3}{|l|}{ Method } \\
\hline Overdose & 27 & 63 \\
\hline Influenza preparations & 10 & 23 \\
\hline Benzodiazepines & 7 & 17 \\
\hline Analgesics & 10 & 23 \\
\hline Ingestion of poison & 14 & 33 \\
\hline Other: gunshot/stab & 2 & 4 \\
\hline \multicolumn{3}{|l|}{ Precipitating event } \\
\hline Relationship problems & 30 & 70 \\
\hline Financial & 4 & 9 \\
\hline Illness & 5 & 12 \\
\hline Depression & 4 & 9 \\
\hline \multicolumn{3}{|l|}{ Premeditated act } \\
\hline Yes planned & 15 & 35 \\
\hline Short term & 6 & 14 \\
\hline Long term & 9 & 21 \\
\hline No impulsive & 28 & 65 \\
\hline \multicolumn{3}{|l|}{ Suicide note written } \\
\hline Yes & 2 & 5 \\
\hline No & 41 & 95 \\
\hline \multicolumn{3}{|l|}{ Alone at time of attempt } \\
\hline Yes & 34 & 79 \\
\hline No & 9 & 21 \\
\hline \multicolumn{3}{|l|}{ Time of attempt } \\
\hline Daytime (06h00 18h00) & 28 & 65 \\
\hline Evening ( $18 \mathrm{~h} 00$ 06h00) & 15 & 35 \\
\hline \multicolumn{3}{|l|}{ Serious attempt } \\
\hline Yes & 12 & 28 \\
\hline No & 31 & 72 \\
\hline \multicolumn{3}{|l|}{ Admitted as inpatient } \\
\hline Yes & 19 & 44 \\
\hline No & 24 & 56 \\
\hline \multicolumn{3}{|l|}{ Desire at time of attempt } \\
\hline Wanted to die & 28 & 65 \\
\hline Making a point/cry for help & 9 & 21 \\
\hline Unsure & 2 & 5 \\
\hline \multicolumn{3}{|l|}{ Feelings about surviving } \\
\hline Glad to be alive & 25 & 58 \\
\hline Unsure & 9 & 21 \\
\hline Angry about surviving & 9 & 21 \\
\hline \multicolumn{3}{|l|}{ Intention to repeat act } \\
\hline Yes & 2 & 5 \\
\hline No/unsure & 41 & 95 \\
\hline
\end{tabular}

\section{Discussion}

In contrast to previous reports of increasing age as a feature of patients with NFSB, ${ }^{10-14}$ the patients in this study were much younger and predominantly in the 18 -30-year age group. Higher incidences of this behaviour have recently been reported in young South Africans. ${ }^{12.14}$ Younger persons may be particularly at risk because of educational and socioeconomic demands, high unemployment rates and unmet expectations. ${ }^{12}$ Among the subjects in this study, relationship problems, financial
Table II. Factors associated with non-fatal repetition

\begin{tabular}{|c|c|c|c|c|}
\hline \multirow[b]{2}{*}{ Factors } & \multicolumn{2}{|c|}{ Repeat NFSB } & \multicolumn{2}{|c|}{ First attempt } \\
\hline & $\bar{N}$ & $\%$ & $\mathrm{~N}$ & $\%$ \\
\hline \multicolumn{5}{|l|}{ Age group (yrs) } \\
\hline 1830 & 5 & 50 & $25^{*}$ & 76 \\
\hline $30 \quad 45$ & 2 & 20 & 7 & 21 \\
\hline$>45$ & 3 & 30 & 1 & 3 \\
\hline \multicolumn{5}{|l|}{ Gender } \\
\hline Male & 1 & 10 & 16 & 48 \\
\hline Female & 9 & 90 & $17^{*}$ & 52 \\
\hline \multicolumn{5}{|l|}{ Children } \\
\hline Yes & 9 & 90 & $17^{*}$ & 52 \\
\hline No & 1 & 10 & 16 & 48 \\
\hline \multicolumn{5}{|c|}{ Past psychiatric history } \\
\hline Yes & 5 & 50 & $6^{*}$ & 18 \\
\hline No & 5 & 50 & 27 & 82 \\
\hline \multicolumn{5}{|c|}{ Seriousness of the attempt } \\
\hline Yes & 6 & 50 & $6^{*}$ & 18 \\
\hline No & 4 & 50 & 27 & 82 \\
\hline \multicolumn{5}{|c|}{ Intention to repeat the act } \\
\hline Yes & 2 & 20 & & \\
\hline No & 6 & 60 & $27^{*}$ & 82 \\
\hline Maybe & 2 & 20 & 6 & 18 \\
\hline \multicolumn{5}{|c|}{ Outcome of the attempt } \\
\hline Admitted & 8 & 80 & $11^{*}$ & 33 \\
\hline Discharged & 2 & 20 & 22 & 67 \\
\hline${ }^{*} p<0.05$. & & & & \\
\hline
\end{tabular}

difficulties, illness and depressed mood were reported as common precipitants of the behaviour. South Africa is undergoing rapid urbanisation 195\% of our subjects lived in the cityl and the stress associated with this relocation may be a contributing factor. ${ }^{30,31}$

Overdosing with common medicines (influenza preparations and analgesics) and the ingestion of household poisons were the most common NFSBs in our subjects. In most cities in the developing world similar medicines are often used for selfharm. ${ }^{3436}$ In a case series from Cape Town the majority of patients stated that they used battery acid because it was readily available in car batteries used as a power source in their unelectrified houses, and also because they were aware of its destructive effects. ${ }^{21,37,38}$ Poisoning is a common form of deliberate self-harm and while suicidal intent is often far lower than in cases of self-immolation and hanging, the mortality rate is high owing to the toxicity of the agents used. Traditional medicines are a cause of accidental, but rarely intentional, poisoning. ${ }^{39}$ Outside the cities these methods are relatively uncommon and their prominence is displaced by pesticides, which are often fatal.

Although the majority of our patients indicated that they had a desire to die at the time of the attempt, they were glad to have 
survived and said they had no intention of repeating the behaviour. Not all people who die following acts of self-harm actually wish to die. ${ }^{40-43}$ Instead, the acts are used to express rage or hostility, or to gain revenge by causing distress to another person. In some cultures this may be seen as the only way to express one's anger with someone. ${ }^{44,45}$ People who do want to kill themselves often do not succeed; in contrast, others with little or no suicidal intent sometimes die as a result of their act. ${ }^{46}$ Many factors affect the outcome, including the degree to which the toxicity of the poison was understood, the speed with which the person comes to clinical attention, and the availability of effective medical treatment.

Significant factors associated with non-fatal repetition in this study included being in the 18 -30-year age group, having children, a past psychiatric history and a current attempt that was deemed medically serious. The link between self-harm and suicide is a strong one. Non-fatal repetition is common after a previous episode of self-harm; about 1 in 6 patients repeats the act over the next year, and 1 in 4 after 4 years. Patients who discharge themselves before completing initial management have a considerably increased rate of repetition. ${ }^{47}$

Interventions for patients who deliberately harm themselves are currently being evaluated. It is of concern that some patients at greatest risk of repeating such behaviour are discharged before management is completed. At Johannesburg Hospital some of the criteria for admission included a history of a previous NFSB, sexual or physical abuse, a low level of education, or if the patient had no children. In addition the behaviour was considered to be more serious if it was a first episode, impulsive, or if the patient was young, had a family history of NFSB and/or a psychiatric illness. Known factors such as unemployment, increasing severity of suicidal ideation, previous psychiatric treatment and personality disorders were not taken into consideration.

These findings emphasise the importance of optimising psychosocial management by staff in accident and emergency departments during the initial stages of treatment, ${ }^{48}$ and the need to develop guidelines for admission to hospital.

This study is limited in its generalisability because most of our study population were inner-city dwellers presenting to the emergency room of a tertiary hospital. Some patients may have been treated/attended to in the emergency room of the hospital but were discharged home or directly to a psychiatric facility before inclusion into the study. The small sample size 143 patients) may have limited our ability to detect statistically meaningful differences when analysing for factors associated with non-fatal repetition.

\section{Conclusion}

NFSB is a major problem in South Africa and the incidence is still increasing. In suggesting effective ways to prevent this problem, we must be realistic and aware of our limited resources. However, acknowledging the seriousness of the situation is a first step towards preventing this unnecessary behaviour.

A significant factor associated with non-fatal repetition includes a past psychiatric history and a medically serious attempt. Hospital-based interventions after admission for NFSB are recommended in an attempt to reduce repetition. In South Africa a reduced number of inpatient beds has meant that medical staff are reluctant to admit patients judged to be at low physical risk; the latter are also often seen as difficult and unrewarding cases. Psychiatric services are increasingly reserved for those with serious mental illness, a term not taken to include most cases of NFSB. The current situation should not be allowed to continue, because NFSB represents a major social and clinical problem. At the least, large-scale intervention studies are required to inform practice and ensure that management of NFSB is less arbitrary in the future.

Improved mental health care, particularly at community level, must be an important part of any strategy to reduce self-harm. Approaches to primary prevention may include increasing peoples' coping skills - possibly offering coping-skill classes at school, and counselling in the community.

Funding was received from the Department of Neurosciences, Division of Psychiatry, University of the Witwatersrand.

The authors would like to acknowledge Dr R Liebenberg for initiating the project and the registrars working at Johannesburg Hospital for interviewing the patients with NFSB.

\section{References}

1. Zimmerman M, Lish JD, Lush DT, Farber NJ, Plescia G, Kuzma MA. Suicidal ideation among urban medical outpatients. J Gen Intern Med 1995: 10: 573-576.

2. Ramsay R, Bagley $C$. The prevalence of suicidal behaviors, attitudes and associated social experiences in an urban population. Suicide Life Threat Behav 1985; 15: 151-167.

3. Paykel ES, Myers JK, Linden hal لJ, Tanner J. Suicidal feelings in the general population: a prevalence study. BrJ Psychiatry 1974; 124: 460-469. 
4. Owens D, House A. General hospital services for deliberate self harm. J R Coll Physicians Lond. 1994; 28: 370-371.

5. Schwab JJ, Wa heit GJ, Holzer CE III. Suicide ideation and behavior in a general population. Dis Nerv Syst 1972; 33: 745-748

6. Beautrais AL, Joyce PR, Julder RT, et al. Prevalence and comorbidity of mental disorders in persons making serious suicide attempts: a case-control study. Am J Psychiatry 1996; 153: 1009-1014.

7. Brent DA, Perper JA, Goldstein CE, et al. Risk factors for adolescent suicide: a comparison of adolescent suicide victims wi h suicidal inpatients. Arch Gen Psychiatry 1988; 45: 58 1-588

8. Moscicki EK, O'Carroll P, Rae DS, et al. Suicide attempts in the Epidemiologic Catchment Area Study. Yale J Biol Med 1988; 61: 259-268.

9. Andrews JA, Lewinsohn PM. Suicidal attempts among older adolescents: prevalence and co-occurrence wi h psychiatric disorders. J Am Acad Child Adolesc Psychiatry 1992: 31: 655-662

10. Holley HL, Fick G, Love EJ. Suicide following an inpatient hospitalisation for a suicide attempt: a Canadian follow-up study. Soc Psychiatry Psychiatr Epidemiol 1998; 33: 543-551

1 1. Soukas J, Lonnquist J. Outcome of attempted suicide and psychiatric consultationrisk factors and suicide mortality during a five-year follow up. Acta Psychiatr Scand 1991; 84: 545-549

12. Schlebusch L. Self-destructive behaviour in adolescents. S Afr MedJ 1985; 68: 792-795.

13. Pillay AL, Pillay YG. A study of deliberate self harm at a Pietermaritzburg general hospital. S Afr Med J 1987; 72: 258-259

14. Cummins RR, Allwood CW. Suicide attempts or threats by children and adolescents in Johannesburg. S Afr MedJ 1984; 66: 726-729.

15. Nielsen B, Wang AG, Bille-Brahe U. Attempted suicide in Denmark IV. A five-year follow up. Acta Psychiatr Scand 1990; 81 : 250-254

16. Soukas J, Suominen $K$, Isometsa $E$, et al. Long-term risk factors for suicide mortality after attempted suicide - findings of a 14-year follow-up study. Acta Psychiatr Scand 2001: 104: 117-121.

17. Nordentoft M, Brerum B, Munck LK, et al. High mortality by natural and unnatural causes: a 10-year follow up study of patients admitted to a poisoning treatment centre after suicide attempts. BMJ 1993; 306: 1637-1641.

18. Mackenzie TB, Popkin MK. Suicide in he medical patient. Int J Psychiatry Med 1987; 17: $3-22$

19. Dannenberg AL, MCNeil JG, Brundage JF, Brookmeyer R. Suicide and HIV infection: mortality follow up of $4147 \mathrm{HIV}$-seropositive military service applicants. JAMA 1996; 276: 1743-1746

20. Pillay AL, van der Veen MB, Wassenaar DR. Non-fatal suicidal behaviour in women - he role of spousal substance abuse and marital violence. S Afr Med J 200 1: 91 : 429-432

21. Wilson DA, Wormald PJ. Battery acid - an agent of attempted suicide in black South Africans. S Afr Med J 1995; 85: 529-53

22. Naidoo P, Pillay BJ. Parasuicide in a general hospital in South Africa. Psychol Rep 1993; 72: $979-982$

23. Schmidtke A, Bille-Brahe U, Deleo D, et al. Attempted suicide in Europe: rates, trends and sociodemographic characteristics of suicide attempters during the period 1989-1992. Results of the WHO/EURO Multicentre Study on Parasuicide. Int J Geriatr Psychiatry 2001; 16: 300-310.

24. Meel BL. Determinants of suicide in the Transkei sub-region of South Africa. Journal of Clinical Forensic Medicine 2003; 10: 71-76.
25. Mhlongo T, Peltzer K. Parasuicide among you $h$ in a general hospital in South Africa. Curationis 1999; 22: $72-76$

26. Peltzer K, Cherian VI, Cherian L. Attitudes toward suicide among South African secondary school pupils. Psychol Rep 1998; 83: 1259-1265.

27. Petronis KR, Samuels JF, Moscicki EK, Anthony JC. An epidemiologic investigation of potential risk factors for suicide attempts. Soc Psychiatry Psychiatr Epidemiol 1990; 25: 193-199.

28. Burrows $S$, Vaez M, Butchart A, Laflamme L. The share of suicide in injury deaths in he South African context: sociodemographic distribution. Public Health 2003; 117: 3-10

29. Gunnell D. Frankel, S. Prevention of suicide: aspirations and evidence. BMJ 1994 308: $1227-1233$

30. Dirks BL. Repetition of parasuicide-ICD-10 personality disorders and adversity. Acta Psychiatr Scand 1998; 98: 208-213.

31. Leon AC, Friedman RA, Sweeney JA, et al. Statistical issues in the identification of risk factors for suicidal behaviour: he application survival analysis. Psychiatr Res 1990; 31: 99-108.

32. Schlebusch L, Vawda NB, Bosch BA. Suicidal behavior in black South Africans. Crisis 2003; 24: 24-28

33. Moosa MYH, Jeenah FY, Pillay A, et al. Non-fatal suicidal behaviour at he Johannesburg General Hospital. South African Psychiatric Review 2005; 104-107.

34. Eddleston M. Patterns and problems of deliberate self-poisoning in the developing world. QJM 2000; 93: 715-731.

35. Thabet $\mathrm{H}$, Brahmi N, Zagdoudi l, et al. Acute self-poisoning with carbamazepine. Presse Med 1999: 28: 955-958

36. Khan MM, Reza H. Benzodiazepine self-poisoning in Pakistan: implications for prevention and harm reduction. J Pak Med Assoc 1998; 48: 293-295.

37. Wormald PJ, Wilson DAB. Battery acid ingestion: a Sou h African phenomenon Clin Otolaryngol 1993; 18: $112-114$.

38. Egigbo PO, Aghaji MAC, Obiako MN. Battery acid intake as a me hod of suicide attempt in Nigeria - family and social antecedents. International Journal of Family Psychiatry 1987; 8: 375-385.

39. Stewart MJ, Steenkamp V, Zuckerman M. The toxicology of African herbal remedies. Ther Drug Monit 1998; 20: $510-516$.

40. Hawton K. Deliberate self-harm. Medicine 1997; 24: 77-80.

41. Hawton K, Catalan J. Attempted Suicide: A Practical Guide to its Nature and Management. Oxford: Oxford Medical Publications, 1987.

42. Abu Al-Ragheb S, Qaryoute S, el-Muhtaseb H. Mortality of burn injuries in Jordan. Burns, including Thermal Injury 1984; 10: 439-443.

43. Williams $H$, Buchan $T$. A preliminary investigation into parasuicide in Salisbury, Zimbabwe - 1979/1980. Cent Afr J Med 1981; 27: 129-135.

44. Maracek J. Psychological approaches to understanding suicide. In: De Silva P, ed Suicide in Sri Lanka. Kandy, Sri Lanka: Institute of Fundamental Studies, 1989: 16 24

45. De Silva $P$. The logic of attempted suicide and its linkage wi h human emotions. In: De Silva P, ed. Suicide in Sri Lanka. Kandy, Sri Lanka: Institute of Fundamental Studies, 1989: 25-40

46. Kessel N. Self-poisoning. BMJ 1965; 2: 1265-70, 1336-1340

47. Crawford MJ, Wessely S. Does initial management affect he rate of repetition of deliberate self harm? Cohort study. BMJ 1998; 317: 985

48. Crawford MJ, Turnbull G, Wessely S. Deliberate self harm assessment by accident and emergency staff - an intervention study. J Accid Emerg Med 1998; 15: 18-22. 